Int. J. Dev. Biol. 56: 919-929 (2012)

doi: $10.1387 / \mathrm{ijdb} .120132 \mathrm{cc}$

\title{
The use of immature oocytes in the fertility preservation of cancer patients: current promises and challenges
}

\author{
CATHERINE M.H. COMBELLES* and GABRIELA CHATEAU \\ Middlebury College, Biology Department, Middlebury, VT, USA
}

\begin{abstract}
Improved oncological treatments permit increased survival rates, although cancer patients remain at risk of losing ovarian function. An attractive option for fertility preservation includes the use of immature oocytes, a strategy which can occur on a rapid timeline and without hormonal stimulation. As a result, cancer therapy can proceed promptly even in patients with hormone-sensitive tumors. Following retrieval, immature oocytes can be cryopreserved at either the immature germinal vesicle or the mature metaphase-Il stage, i.e. either before or after in vitro maturation (IVM). We present a critical review of previous human studies on the cryopreservation of immature oocytes. Evaluations include in vitro developmental competence upon thawing/warming, or organization of the spindle and chromosomes. Reported successes vary, perhaps in relation to the source of the oocytes and protocols for cryopreservation and IVM. Weaknesses exist with the experimental designs implemented to date, so caution must be exercised before considering the use of immature oocytes to be a safe and reliable practice in the fertility preservation of cancer patients. To date, results indicate that with current protocols, it may be best to cryopreserve immature oocytes after IVM at the metaphase-II stage. Nonetheless, efficacy remains very low. Future efforts should tailor and optimize not only cryopreservation, but also IVM protocols for use in either germinal vesicle or metaphase-II oocytes, together with a comprehensive assessment of oocyte function and developmental competence to term. Despite current challenges, the burgeoning field of immature oocyte cryopreservation constitutes a promising option for cancer patients with impaired ovarian function.
\end{abstract}

KEY WORDS: immature oocyte, fertility preservation, cryopreservation, cancer, in vitro maturation

\section{Why target immature oocytes in cancer patients?}

In the last few decades, the incidence of cancer and the likelihood of survival have risen across the globe. A little over 1 in 3 women in North America are diagnosed with cancer every year. This constitutes an overwhelming number of young women of reproductive age undergoing chemotherapy, radiotherapy, and other oncologic treatments; an estimated $9 \%$ of cancer survivors are 20-39 years old in the United States. Invasive cancers are treated aggressively through chemotherapy, radiotherapy and surgeries to remove cancerous cells and masses. Unfortunately such treatments create irreversible damage to the gonads and possible sterility (reviewed by Anchan and Ginsburg, 2010). Depending on the type and dose, oncological therapies may result in damage and/or loss of not only germ cells but also the supporting somatic compartments of the ovarian follicle. Due to the women's finite number of oocytes and the irreplaceable nature of the pool of primordial follicles, fertility may be markedly decreased. It is therefore essential that fertility preservation be considered prior to the chemotherapy and radiotherapy treatments in cancer patients of reproductive age.

Several options are available, including the preservation of cellular material prior to cancer therapy, and treatments to decrease reproductive damage due to chemotherapy and radiation. General strategies to minimize reproductive damage include using lower doses of cytotoxic chemicals, lower toxicity chemicals, and attempting conservative surgery. Slightly more invasive methods to diminish the damage involve:i) ovarian transposition, whereby the ovaries are surgically moved away from the area of radiotherapy, and ii) the administration of agents such as gonadotropin releas-

\footnotetext{
Abbreviations used in this paper: COC, cumulus-oocyte complex; hCG, human chorionic gonadotropin; GV, germinal vesicle; ICSI, intracytoplasmic sperm injection; IVM, in vitro maturation; M-I, metaphase-I; M-II, metaphase-II.
}

\footnotetext{
*Address correspondence to: Catherine Combelles. Middlebury College, Biology Department, McCardell Bicentennial Hall 346, Middlebury, VT 05753, USA. Tel: +1-802-443-5251. Fax: +1-802-443-2072. E-mail: ccombell@ middlebury.edu

Final, author-corrected PDF published online: 5 February 2013.
} 
ing hormone agonists ( $\mathrm{GnRH}-\mathrm{a})$ that are presumed to increase the ovarian cells resistance to the detrimental effects of cancer treatment by reducing ovarian follicular growth and cell division, although the exact mechanisms and efficacy aren't yet established (Xu etal., 2011). The current options for preserving cellular material include embryo, ovarian tissue, and oocyte cryopreservation. Embryo cryopreservation necessitates typically 2-6 weeks of pituitary down-regulation and ovarian stimulation prior to oocyte retrieval, and it also requires the patient to be of post-pubertal age as well as the availability of a sperm source. Ovarian tissue cryopreservation is a relatively new procedure with varying success. It entails freezing ovarian tissue fragments with intact primordial follicles containing immature oocytes. Oocyte cryopreservation is a third option for fertility preservation, which involves aspirating oocytes from antral follicles and cryopreserving them. The oocytes can be collected and frozen at either the mature or metaphase-II (M-II) stage of development or the immature, prophase-l or germinal vesicle (GV) stage. As presented below, immature oocytes may be targeted in order to circumvent issues of: hormonal stimulation in sensitive cancers, prolonged fertility procedures that delay cancer treatment, the need for a sperm source, and the creation of embryos prior to cancer therapy. There are benefits and detriments in all the fertility options, however, for a large subset of cancer patients the cryopreservation of immature oocyte represents a tangible and attractive option (Table 1).

Minimizing or eliminating the need for hormonal stimulation

Embryo cryopreservation is a relatively successful form of fertility preservation in women needing cancer therapies. But to obtain a sufficient number of mature metaphase-II oocytes, embryo cryopreservation relies on ovarian stimulation, a protocol that is not applicable in hormone sensitive cancers. Breast, prostate, ovarian and endometrial cancers are all hormone sensitive as they rely on

TABLE 1

\section{ADVANTAGES AND DRAWBACKS OF CRYOPRESERVING IMMATURE OOCYTES WHEN COMPARED \\ TO THE PRESERVATION OF OTHER CELLULAR MATERIAL}

\begin{tabular}{|c|c|c|}
\hline Cryopreservation Options & Advantages & Drawbacks \\
\hline Embryos & Relatively high pregnancy rates & $\begin{array}{l}\text { Ovarian stimulation } \\
\text { Need a partner } \\
\text { Pubertal age }\end{array}$ \\
\hline Ovarian tissue & $\begin{array}{l}\text { No ovarian stimulation } \\
\text { Prepubescent females } \\
\text { Numerous immature oocytes } \\
\text { Partner not required }\end{array}$ & $\begin{array}{l}\text { Risk of returning cancerous tissue } \\
\text { Low pregnancy rates } \\
\text { IVM required } \\
\text { Surgery to harvest ovarian tissue }\end{array}$ \\
\hline Mature oocytes & $\begin{array}{l}\text { No IVM } \\
\text { Clinical efficacy on the rise } \\
\text { Partner not required }\end{array}$ & $\begin{array}{l}\text { Ovarian stimulation } \\
\text { Cellular damages to the oocyte } \\
\text { Low pregnancy rates }\end{array}$ \\
\hline Immature oocytes & $\begin{array}{l}\text { No ovarian stimulation } \\
\text { Prepubescent females } \\
\text { No delay in cancer treatment } \\
\text { Partner not required }\end{array}$ & $\begin{array}{l}\text { Low success } \\
\text { IVM required }\end{array}$ \\
\hline
\end{tabular}

Slow-Freeze/Thaw

Fig. 1. Diagram depicting how immature oocytes may be used for fertility preservation and restoration. Immature germinal vesicle (GV) stage oocytes can either be in vitro matured prior to cryopreservation or cryopreserved before in vitro maturation (IVM) to metaphase-II (M-II), followed by fertilization with intracytoplasmic sperm injection (ICSI).

hormones in order to survive and grow. Ovarian hyperstimulation is associated with high estradiol levels, which are deemed unsafe to hormone sensitive tumors. Immature oocytes, on the contrary, can be collected at any point of the menstrual cycle with minimal or no stimulation of the ovaries (Chian et al., 2000; Nogueira et al., 2012).

\section{Circumventing the use of sperm or the creation of embryos}

Young women and teenagers without partners, girls not yet of reproductive age, and couples with moral or religious objections to embryo cryopreservation are often afflicted by malignancies. Women may thus be faced with the stress of choosing between a sperm bank or risking an inability to bear a child later in life. The use of immature oocytes allows the liberty to preserve fertility without actual fertilization of the oocyte prior to freezing.

\section{Shortening the timing between the preservation of fertility potential and cancer treatment}

A typical in vitro fertilization cycle includes several weeks of ovarian stimulation in order to achieve multifollicular development prior to oocyte retrieval. Cancer patients often do not have an indeterminate amount of time to spare in order to preserve their fertility. To achieve cancer remission, most cancers require immediate chemotherapy or radiotherapy treatment. Cancer patients are thus in need of quick and efficient fertility therapy that does not delay cancer treatment regimens necessary for patient survival.

\section{How may immature oocytes be used?}

Immature oocytes represent an attractive and minimally invasive option. Immature oocytes can be retrieved with ultrasound-guided transvaginal aspiration, avoiding surgical procedures. With the puncture of multiple antral follicles, a large enough number of oocytes may hopefully be obtained for more than one or two embryo transfer attempts. Further, immature oocytes are retrieved promptly with no time delay in cancer treatment. IVM cycles characteristically entail few preparatory steps with minimal or without priming with gonadotropins (reviewed by Nogueira et al., 2012). Notably, a priming approach with human chorionic gonadotropin (hCG) alone allows oocyte retrieval between days 10-14 (Chian et al., 2000). Rapid intervention is possible thanks to the retrieval oocytes regardless 
of the phase of the menstrual cycle; as proofs-of-concepts, mean times between first consultation and oocyte retrieval spanned 8-13 days in a total of 104 breast cancer patients (Huang et al., 2010; Shalom-Paz et al., 2010).

The immature oocyte may be used in one of two ways: 1) the GV stage oocyte undergoes in vitro maturation (IVM) and is then frozen/cooled or 2) the GV stage oocyte is cryopreserved and upon thawing/warming it undergoes IVM (Fig. 1). Successful cases have been presented when cryopreserving at either the GV or M-II (post-IVM) stage. The first live births from the freezing of immature and mature (following IVM) oocytes occurred in 1998 and 2009, respectively (Tucker et al., 1998; Chian et al., 2009a). These births provide a proof-of-principle for the cryopreservation of immature oocytes. However, due to variable and limited results, the clinical efficacy of using immature oocytes for fertility preservation remains uncharted.

Currently, two procedures exist for the cryopreservation of oocytes, namely slow-freezing and vitrification (reviewed by Stachecki and Cohen, 2004). Historically, the slow-freezing method of cryopreservation is used widely, and it has been used to freeze both mature and immature oocytes. The process involves a lower concentration of cryoprotectants than vitrification, reducing toxicity to the oocyte. The oocyte is then slowly cooled to a temperature of $-35^{\circ} \mathrm{C}$ and thawing of the embryo occurs at a rapid pace to avoid recrystallization of water in the cell, a process that could cause damage to the internal structures of the cell. Vitrification is an alternative cryopreservation method, which uses elevated concentrations of highly toxic cryoprotectants and a rapid cooling pace to achieve a glass-like, vitrified oocyte. Vitrification avoids the potential crystallizations that can occur in moisture rich areas of the cell during cooling and warming; however, the high levels of toxic cryoprotectants used to dehydrate the cell may limit cryopreservation success. Early studies relied heavily on the use of slow-freezing; however, vitrification has shown rising success rates with in vivo matured oocytes although slow-freezing protocols may not yet be fully optimized either (reviewed by Edgar and Gook, 2012).

In comparison to a mature M-II oocyte, an immature oocyte arrested in prophase of meiosis-I varies in its internal state (Fig. 2). In a GV oocyte, the chromosomes are not fully condensed and they are contained within the nuclear membrane; secondly the temperature sensitive spindle has not yet formed. The spindle is composed of dynamically instable microtubules, and it is crucial to the formation of a euploid oocyte. Cryoprotectants and low temperatures can cause spindle disorganization and/or depolymerization of microtubules (reviewed by Mandelbaum et al., 2004), in turn putting the zygote at risk for aneuploidy. GV oocytes also contain microtubules, but they are ones characteristic of cells in pre-M phase cells. These microtubules are less dynamically instable than during subsequent M-phase, and with such increased stability may come a heightened ability to withstand insults associated with cryopreservation. It has thus been proposed that freezing GV stage oocytes rather than post-IVM M-II oocytes may reduce the risk of aneuploidy. Further, in vitro maturing oocytes prior to cryopreservation may place additional stresses on the oocyte, perhaps rendering it less capable of withstanding the specific insults of cryopreservation. GV oocytes have thus been postulated as a potentially superior stage to freeze. However, only evidence can confirm when the best time to cryopreserve immature oocytes is, either prior to or following IVM (Fig. 1). All relevant human studies to date (up through June
2012) are synthesized below, together with a critical evaluation of their strengths and limitations. It must also be noted that all cited data were computed out of the total number of available or starting oocytes. This permits an appropriate comparison of results across studies, with the further advantage of representing overall yields that are clinically relevant. Unless noted otherwise, all studies discussed herein are in human.

\section{Cryopreservation at the germinal vesicle stage}

Table 2 summarizes the ranges of values obtained from a total of 23 studies that cryopreserved human oocytes at the GV stage, 14 and 12 of which used slow-freezing or vitrification protocols, respectively (Mandelbaum et al., 1988; Toth et al., 1994a; Toth et al., 1994b; Baka et al., 1995; Son et al., 1996; Park et al., 1997; Chung et al., 2000; Goud et al., 2000; Wu et al., 2001; Boiso et al., 2002; Chen et al., 2004; Fuchinoue et al., 2004; Isachenko et al., 2006; Cao et al., 2009; Fasano et al., 2010; Al-Khtib et al., 2011; Combelles etal., 2011; Criado et al., 2011; Liu et al., 2011; Versieren et al., 2011; Zhang et al., 2011; Fasano et al., 2012; Wang et al., 2012). Seventy percent (16/23) of studies evaluated the in vitro developmental competence of cryopreserved GV oocytes based on fertilization, cleavage, and in some instances even blastocyst formation. Twenty-two percent (5/23) of studies examined instead spindle and/or chromosome organization. It is also relevant to note that most studies (87\%; 20/23) tested oocytes obtained from ovarian stimulation, representing oocytes that failed to mature in vivo.

Table 2 convincingly demonstrates the considerable degree of

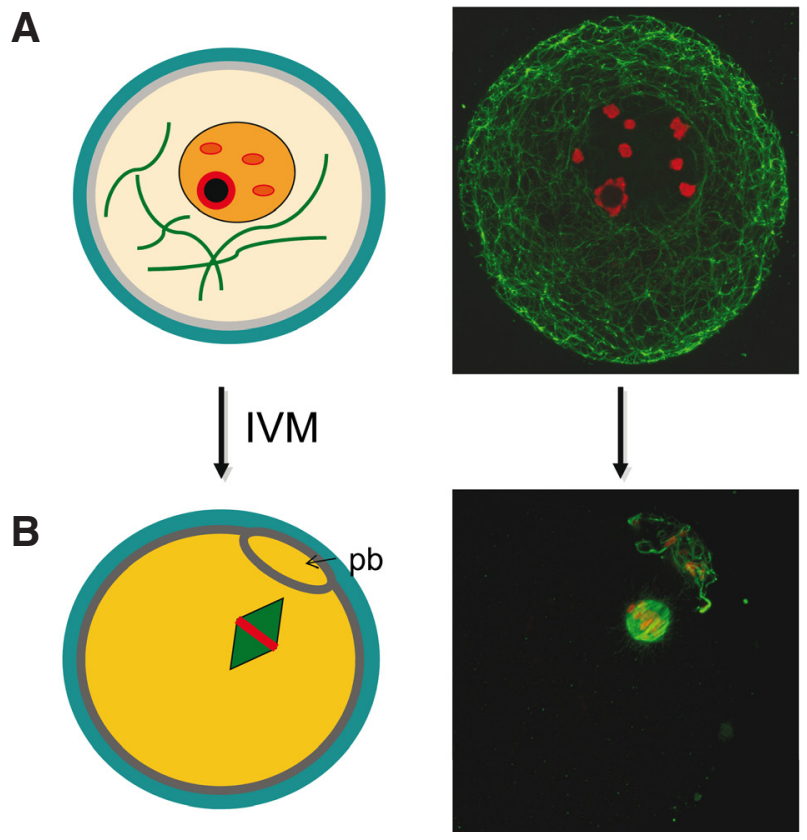

Fig. 2. Germinal vesicle (A) and metaphase-II (B) human oocytes vary in critical cellular features, and thus perhaps in their ability to withstand cryoinjuries. At the germinal vesicle stage (prophase-l), oocytes have an intact nucleus with partially condensed chromatin and microtubules characteristic of interphase; in contrast, metaphase-/l oocytes contain a meiotic spindle with dynamic microtubules and condensed chromosomes. Although not detailed here, the ooplasm, organelles, and membranes also differ between the two meiotic stages, as generally depicted with distinct color shades. (IVM: in vitro maturation; pb: polar body). 
variability in the data for each measured developmental outcome and whether cryopreserving with slow-freezing or vitrification. Interestingly, there are no notable differences in the maturation and in vitro developmental competencies over the years that the studies span (from 1988-2012). It is only with survival rates that there appears to be an overall improvement over time, particularly when comparing data from the 1990's to studies reported in the last ten years with slow-freezing.

When it comes to the evaluation of spindles following IVM of cryopreserved GV oocytes, 1 to $35 \%$ normal spindles were reported out of the total number of starting oocytes (Baka et al., 1995; Boiso et al., 2002; Combelles et al., 2011; Wang et al., 2012). Four of the studies reported $1 \%, 5 \%, 9 \%$, and $35 \%$ normal spindles with slow-freezing of GV oocytes, when compared to $26 \%$ with vitrification (Combelles et al., 2011). There is thus variation among studies in the ability of cryopreserved GV oocytes to support the formation of a bipolar spindle. Importantly, significant differences exist in the modes of spindle evaluation, with respect to the techniques (conventional 2-D fluorescence versus confocal laser scanning 3-D microscopy) and the categorization criteria (degree and types of spindle aberrations). It is thus not possible to compare spindle outcomes across reports. Further, our understanding of what constitutes a truly normal human M-II spindle is not complete and thus, even with state-of-the-art imaging, the biological validity of criteria used for spindle categorization may be argued. We also do not yet grasp the developmental impact, if any, of slight irregularities in M-II oocyte spindles. Not all of the aforementioned studies used 3-D imaging and measurements as performed by Combelles et al., (2011) and Wang et al., (2012); further, rather stringent criteria were applied when assessing the normalcy of the spindle, with an intermediate categorization that included bipolar spindles with only slight abnormalities. Remaining studies (based on 2-D fluorescence alone) limited the spindle categorizations as either normal or abnormal (Fig. 3). Nuances may thus have been missed, although the biological significance of additional intermediate categories remains uncertain.

Such argument about potential limitations with current spindle assessments can also be applied to the evaluation of chromosomes, for which the use of a total DNA stain in intact cells can be particularly limiting. Ideally, cytogenetic analyses will be employed to establish the ploidy of M-II oocytes that result from the in vitro maturation of cryopreserved GV oocytes. Thus far, a single study dating back to 1997 reported a $78 \%(n=27)$ incidence of cytogenetic abnormalities with slow-freezing of GV oocytes when compared to $32 \%(n=44)$ in non-frozen oocytes (Park et al., 1997). Future studies thus remain to document unequivocally the ability of cryopreserved GV oocytes

TABLE 2

\section{PERCENT RANGES OF LABORATORY OUTCOMES WITH THE CRYOPRESERVATION OF IMMATURE HUMAN OOCYTES AT THE GERMINAL VESICLE STAGE}

\begin{tabular}{ccc} 
Outcomes & Slow-Freezing & Vitrification \\
\hline Survival & $16-86$ & $46-94$ \\
Maturation & $0-62$ & $0-77$ \\
Fertilization & $0-43$ & $4-56$ \\
Cleavage & $0-16$ & $1-47$ \\
Blastocyst & $0-1$ & $0-12$ \\
\hline
\end{tabular}

All percentages are reported out of the total number of starting oocytes (see text for supporting citations).
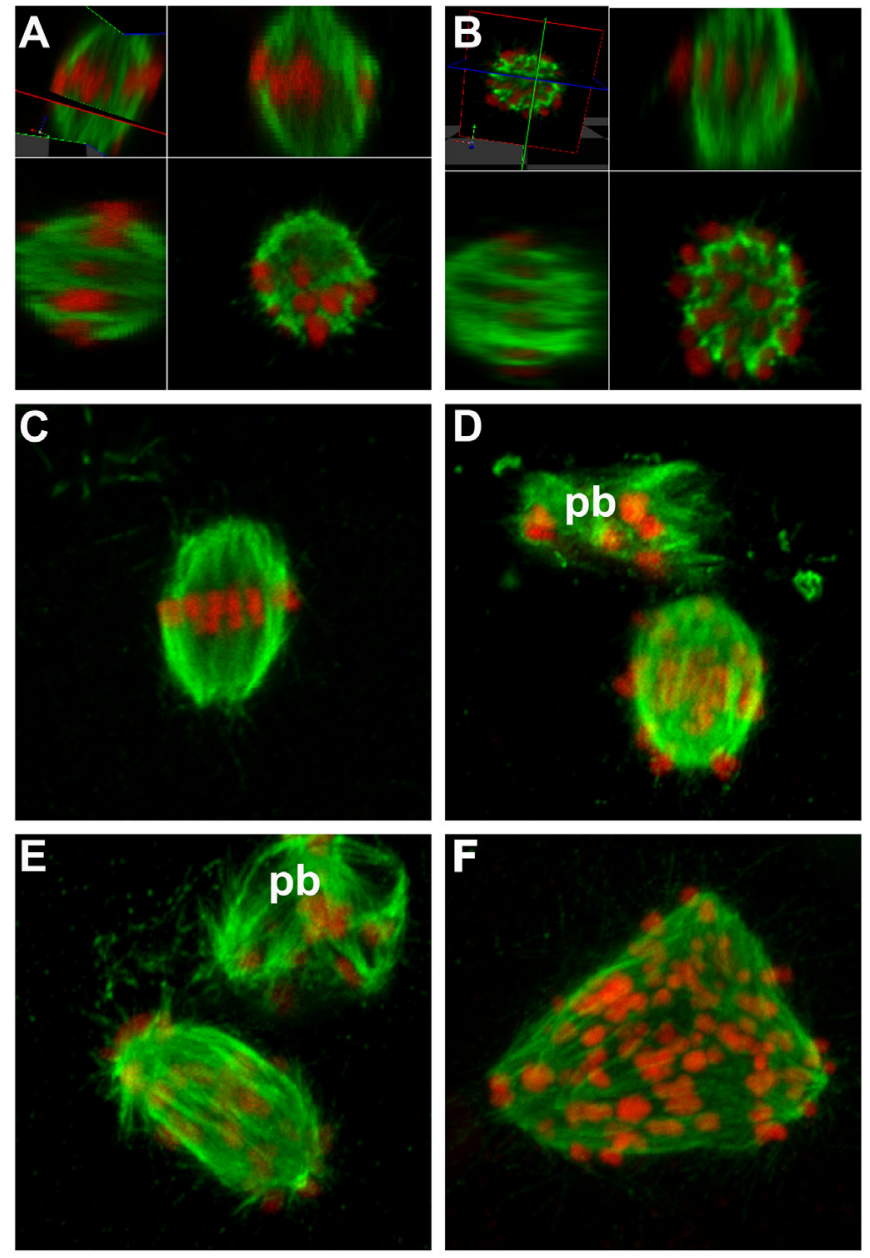

Fig. 3. The organization of human spindles and chromosomes can be ascertained with increased certainty and accuracy with confocal laser scanning microscopy. Three-dimensional (3-D) projections of optical sections illustrate: deemed normal bipolar spindles (C,D), with chromosomes aligned at the equatorial region (C) or most chromosomes aligned with the exception of several chromosomes dispersed to other spindle regions (D); a nearly normal bipolar spindles with minor irregularities and dispersed chromosomes (E); an abnormal, not bipolar spindles with dispersed chromosomes (F). (A) and (B) demonstrate the value of 3-D imaging with the bottom right panel showing the spindle orientation as mounted on the slide versus the other three panels demonstrating orthogonal sections (in $x, y$, and $z$ planes). The latter views reveal the bipolarity of the spindle, an organization that couldn't be ascertained without 3-D imaging. Orthogonal sectioning permits exact categorization of spindles and chromosomes in all oocytes, as well as 3-D morphometric measurements, such as spindle length, width, and volume (as used previously by Combelles et al., 2011 and Wang et al., 2012). (pb: polar body).

to complete meiosis without chromosomal errors.

Caution must be used when interpreting the data presented in Table 2, since some of the studies included were of particularly small sample sizes. This was notably the case for all reports with the highest success rates: for slow-freezing, the $62 \%$ and $43 \%$ maturation and fertilization rates were obtained from a total of only 21 oocytes (Chen et al., 2004) and for vitrification, the 77\%, 56\%, and $47 \%$ maturation, fertilization, and cleavage rates were from a total of 30 oocytes (Fuchinoue et al., 2004). Also with vitrification, 
the rather high $12 \%$ blastocyst formation rate was obtained from a mere 17 starting oocytes (Chung et al., 2000). Most other results were based on acceptable sample sizes, but it is notable that improved rates are all derived from studies with extremely small sample sizes. Future reports on the developmental competence of cryopreserved immature oocytes should thus aim to include a large set of starting oocytes.

Since Table 2 reports the ranges of percentages across studies, histograms that show the distribution of each outcome are presented in Fig. 4. The histograms indicate that there are more reports with increased survival, maturation, and even fertilization with vitrification when compared to slow-freezing. Similarly, improved cleavage rates were reported with vitrification over slow-freezing (Fig. 4). With respect to later developmental competence, only one study reported blastocyst formation with slow-freezing (1\%), in contrast to five studies with vitrification $(0,0,1,3$, and $12 \%)$. Obviously, only limited conclusions can be reached from such comparisons, which are flawed by the inherent variability in protocols and experimental design across studies. More convincing would be reports that aim to compare the success of slow-freezing and vitrification in GV oocytes within a single study.

Three studies have conducted a direct comparison of outcomes when cryopreserving GV stage oocytes with either slow-freezing or vitrification protocols (Fasano et al., 2010; Combelles et al., 2011; Zhang et al., 2011). All three studies used denuded oocytes that failed to mature following ovarian stimulation for intracytoplasmic sperm injection (ICSI). Survival was comparable with slow-freezing and vitrification protocols, and there were also no statistical differences in polar body extrusion. However, it is worth noting that maturation rates were extremely low (0-9\%) in one study (Fasano et al., 2010), and rather low (14-23\%) in another (Zhang et al., 2011). There was no comparison non-cryopreserved group in either of these two studies. In contrast, 39\% and $36 \%$ of available oocytes matured to M-II with slowfreezing and vitrification, respectively; in comparison, non-cryopreserved oocytes matured to M-II at an efficiency of $79 \%$ (Combelles et al., 2011). Two of the three studies reported on developmental competence in vitro but at very low efficiencies, with no fertilization with slow-freezing in comparison to $1.3 \%$ and $4 \%$ with vitrification (Fasano et al., 2010; Zhang et al., 2011). There was no further developmental progression. The third study reported on spindle and chromosome organization with 3-D microscopy; the incidences of M-II oocytes with normal bipolar spindles out of the total number of starting oocytes were $9 \%$ and $26 \%$ for slow-freezing and vitrification, respectively (versus $68 \%$ in the non-cryopreserved group) (Combelles et al., 2011). There was also evidence for increased asynchrony in cell cycle progression for GV oocytes that were slow-frozen when compared to vitrified. Taken together, vitrification may represent a slightly superior protocol over slow-freezing for the cryopreservation of GV stage oocytes. However, the data remain preliminary, based solely on failed to mature denuded oocytes, with low maturation rates and no comparison non-cryopreserved oocytes in two of the studies. Lastly, only one of the studies adopted a sibling oocyte design, the importance of which is discussed below (Combelles et al., 2011).

\section{Cryopreservation at the M-II stage, post in vitro matu- ration}

A handful of past reports have instead focused on the cryopreservation of in vitro matured M-II human oocytes. It must be acknowledged that most of the human studies reporting on the cryopreservation of in vitro matured M-II oocytes pertain to immature oocytes collected in conjunction with ovarian tissue banking. These studies are presented below when discussing the past uses of immature oocytes for fertility preservation in cancer patients, but reviewed next are the few reports that focused on the cryopreservation of M-II oocytes following IVM, from which further insight about outcomes and overall effectiveness can be gleaned.

A first birth from a vitrified in vitro matured oocyte resulted from the retrieval of 19 immature oocytes (18 GV stage) in a natural menstrual cycle (Chian et al., 2009a). The case involved a 27year old woman with tubal disease and polycystic ovaries as part of a clinical trial. Eight-nine percent of oocytes extruded a polar body, $25 \%$ survived (4/16), $75 \%$ fertilized (3/4), 3 embryos were
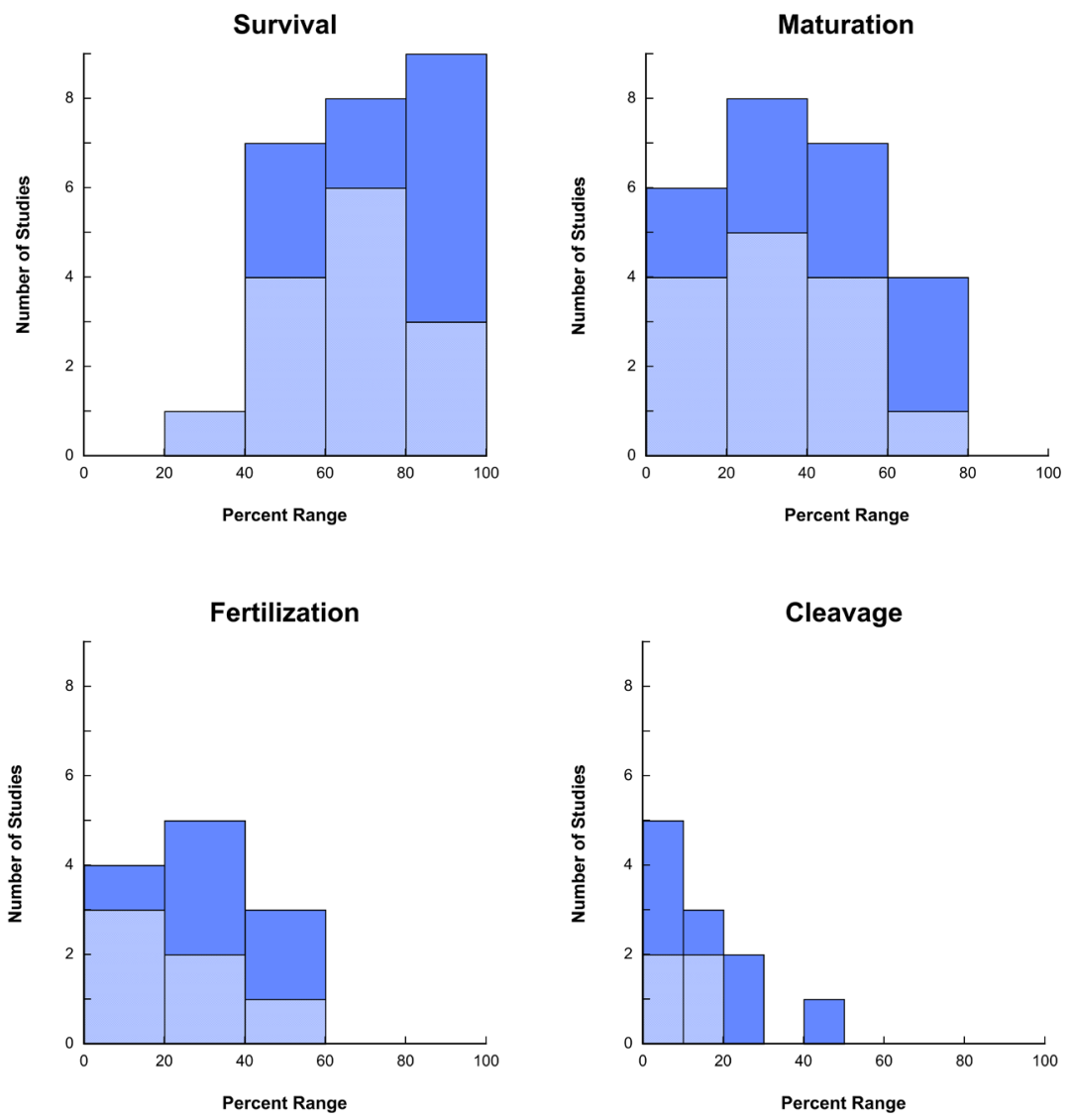

Fig. 4. Survival, maturation, fertilization, and cleavage rates vary widely with the slow-freezing (light blue) and vitrification (dark blue) of immature oocytes at the germinal vesicle stage. Histograms show the distribution of studies within a percent range for each outcome measure. Results are reported out of the total number of starting oocytes (see text for supporting citations). 
transferred resulting in a singleton pregnancy and birth. A subsequent study in 2008 examined the utility of rescued IVM together with cryopreservation in an attempt to increase the pool of total fertilizable oocytes (Chang et al., 2008). From a total of 29 in vitro matured oocytes (that were failed to mature in vivo GV oocytes), $79 \%$ survived, $48 \%$ fertilized, $41 \%$ cleaved, and $7 \%$ developed to blastocyst. Together with cryopreservation, rescued IVM can thus provide an additional pool of fertilizable oocytes, although developmental competency is compromised when compared to the vitrification of in vivo matured oocytes (with $53 \%$ blastocyst formation) (Chang et al., 2008).

Providing further insight into the efficiency of cryopreserving M-II oocytes is a study testing the effectiveness of vitrifying in vivo versus in vitro matured oocytes (Chian et al., 2009b). Patients $(n=20)$ were recruited as part of a clinical trial on IVM, and immature oocytes $(n=290)$ were obtained during the mid-follicular phase (days 1014) with hCG injection $36 \mathrm{hrs}$ prior to retrieval. For comparison, in vivo matured M-Il oocytes ( $\mathrm{n}=399)$ were obtained following ovarian stimulation. While all in vitro developmental measures were significantly improved with in vivo when compared to in vitro matured cryopreserved oocytes, a rather encouraging implantation rate per embryo of $9.6 \%$ was obtained in the IVM group (versus $19.1 \%$ with in vivo maturation). The live-birth rate per cycle started was $20 \%$ and $39.5 \%$ with the combination of cryopreservation and in vitro and in vivo maturation, respectively (Chian et al., 2009b). There were no associated adverse pregnancy outcomes with these four births from in vitro matured vitrified oocytes, thereby buttressing the potential utility of immature oocytes, notably following IVM for fertility preservation. Another strength of this study is that oocytes were obtained without gonadotropin stimulation during a short cycle, a particular advantage for translational use in patients about to undergo cancer therapy.

It is relevant to note that all of the aforementioned studies on the use of M-II oocytes (post-IVM) employed vitrification; these studies were also performed rather recently by laboratories that are different from all studies reported above for freezing at the GV stage. It follows that protocols differed significantly, and it is thus difficult to compare the effectiveness of freezing at the GV or M-II stage based on the studies presented herein thus far.

\section{Direct comparisons of cryopreservation at either the germinal vesicle or M-II (post in vitro maturation) stage}

Studies that undertook a side-by-side comparison of freezing at either the GV or M-II (post-IVM) stage are irrefutably superior in design, notably when compared to studies evaluating the freezing of either GV or M-II oocytes alone. With a side-by-side approach, cryopreservation successes can be compared directly with the source of the oocytes, as well as all laboratory and manipulator conditions kept constant. Yet, all side-by-side comparisons evaluating the best stage to freeze oocytes at have not incorporated one final crucial aspect of an optimal experimental design; ideally, sibling oocytes (that is oocytes from a same patient) should be allocated randomly to either test groups (for cryopreservation at either the GV or M-II stage). A sibling oocyte design thus allows patient-specific variables to be controlled for.

Atotal of eight studies compared directly cryopreservation at the GV or post-IVM stage, only two of which employed a sibling oocyte

TABLE 3

SIDE-BY-SIDE COMPARISONS OF THE CRYOPRESERVATION OF IMMATURE OOCYTES, EITHER AT THE GV OR M-II (POST-IVM) STAGE

\begin{tabular}{|c|c|c|c|c|c|c|c|c|c|c|}
\hline Study & Oocyte Source $^{a}$ & $\begin{array}{l}\text { Sibling } \\
\text { Design }\end{array}$ & $\begin{array}{l}\text { Cryo. } \\
\text { Method }\end{array}$ & Survival & Maturation & $\begin{array}{l}\text { Normal } \\
\text { Spindles }\end{array}$ & $\begin{array}{l}\text { Normal } \\
\text { Chromosomes }\end{array}$ & $\begin{array}{l}\text { Fertilization/ } \\
\text { Activation }\end{array}$ & Cleavage & Blastocyst \\
\hline Baka et al. 1995 & $\begin{array}{l}\text { Stimulated } \\
\text { Failed-mature } \\
\text { Denuded }\end{array}$ & No & Slow-freezing & $\begin{array}{l}\text { GV: } 63 \\
\text { M-II: } 58\end{array}$ & GV: 43 & $\begin{array}{l}\text { GV: } 35 \\
\text { M-II: } 22 \\
\text {-Fz: } 84\end{array}$ & $\begin{array}{l}\text { GV: } 36 \\
\text { M-II: } 26 \\
\text {-Fz: } 87\end{array}$ & & & \\
\hline \multirow[t]{2}{*}{ Chung et al. 2000} & $\begin{array}{l}\text { Unstimulated } \\
\text { Surgeries } \\
\text { COC }\end{array}$ & No & Vitrification & $\begin{array}{l}\text { GV: } 63 \\
\text { M-II: } 56\end{array}$ & $\begin{array}{l}\text { GV: } 40 \\
\text { M-II: } 70\end{array}$ & & & $\begin{array}{l}\text { GV: } 23 \\
\text { M-II: } 22\end{array}$ & $\begin{array}{l}\text { GV: } 23 \\
\text { M-II: } 22\end{array}$ & $\begin{array}{l}\text { GV: } 10 \\
\text { M-II: } 8\end{array}$ \\
\hline & $\begin{array}{l}\text { Stimulated } \\
\text { Enrolled patients } \\
\text { COC }\end{array}$ & No & Vitrification & $\begin{array}{l}\text { GV: } 65 \\
\text { M-II: } 100\end{array}$ & $\begin{array}{l}\text { GV: } 53 \\
\text { M-II: } 71\end{array}$ & & & $\begin{array}{l}\text { GV: } 35 \\
\text { M-II: } 59\end{array}$ & $\begin{array}{l}\text { GV: } 29 \\
\text { M-II: } 59\end{array}$ & $\begin{array}{l}\text { GV: } 12 \\
\text { M-II: } 23\end{array}$ \\
\hline Goud et al. 2000 & $\begin{array}{l}\text { Stimulated } \\
\text { Failed-mature } \\
\text { Partial COC }\end{array}$ & No & Slow-freezing & $\begin{array}{l}\text { GV: } 48 \\
\text { M-II: } 84\end{array}$ & $\begin{array}{l}\text { GV: } 30 \\
\text { M-II: } 73 \\
\text {-Fz: } 70\end{array}$ & & & $\begin{array}{l}\text { GV: } 17 \\
\text { M-II: } 29 \\
\text {-Fz: } 50\end{array}$ & $\begin{array}{l}\text { GV: } 16 \\
\text { M-II: } 26 \\
\text {-Fz: } 41\end{array}$ & \\
\hline Boiso et al. 2002 & $\begin{array}{l}\text { Stimulated } \\
\text { Failed-mature } \\
\text { Denuded }\end{array}$ & No & Slow-freezing & $\begin{array}{l}\text { GV: } 73 \\
\text { M-II: } 56\end{array}$ & $\begin{array}{l}\text { GV: } 53 \\
\text { M-II: } 73\end{array}$ & $\begin{array}{l}\text { GV: } 5 \\
\text { M-II: } 16 \\
\text {-Fz: } 72\end{array}$ & $\begin{array}{l}\text { GV: } 5 \\
\text { M-II: } 19 \\
\text {-Fz: } 82\end{array}$ & & & \\
\hline Cao et al. 2009 & $\begin{array}{l}\text { Stimulated } \\
\text { IVM cycles } \\
\text { COC or denuded }\end{array}$ & No & Vitrification & $\begin{array}{l}\text { GV: } 85 \\
\text { M-II: } 86\end{array}$ & $\begin{array}{l}\text { GV: } 43 \\
\text { M-II: } 85\end{array}$ & & & $\begin{array}{l}\text { GV: } 27 \\
\text { M-II: } 51 \\
\text {-Fz: } 66\end{array}$ & $\begin{array}{l}\text { GV: } 19 \\
\text { M-II: } 34 \\
\text {-Fz: } 58\end{array}$ & $\begin{array}{l}\text { GV: } 0 \\
\text { M-II: } 0 \\
\text {-FZ: } 27\end{array}$ \\
\hline Versieren et al. 2011 & $\begin{array}{l}\text { Stimulated } \\
\text { Failed-mature } \\
\text { Denuded }\end{array}$ & No & Slow-freezing & $\begin{array}{l}\text { GV: } 76 \\
\text { M-II: } 72\end{array}$ & $\begin{array}{l}\text { GV: } 56 \\
\text { M-II: } 72\end{array}$ & & & $\begin{array}{l}\text { ^GV: } 80 \\
\text { M-II: } 75 \\
\text {-Fz: } 82\end{array}$ & $\begin{array}{l}\text { ^GV: } 88 \\
\text { M-II: } 76 \\
\text {-Fz: } 93\end{array}$ & \\
\hline Fasano et al. 2012 & $\begin{array}{l}\text { Stimulated } \\
\text { Failed-mature } \\
\text { Denuded }\end{array}$ & Yes & Vitrification & $\begin{array}{l}\text { GV: } 81 \\
\text { M-II: } 87\end{array}$ & $\begin{array}{l}\text { GV: } 0 \\
\text { M-II: } 29\end{array}$ & & & $\begin{array}{l}\text { \#GV: } 0 \\
\text { M-II: } 21\end{array}$ & $\begin{array}{l}\text { \#GV: } 0 \\
\text { M-II: } 11\end{array}$ & $\begin{array}{l}\text { \#GV: } 0 \\
\text { M-II: } 0\end{array}$ \\
\hline Wang et al. 2012 & $\begin{array}{l}\text { Stimulated } \\
\text { Failed-mature } \\
\text { Denuded }\end{array}$ & Yes & Slow-freezing & $\begin{array}{l}\text { GV: } 70 \\
\text { M-II: } 71\end{array}$ & $\begin{array}{l}\text { GV: } 36 \\
\text { M-II: } 76 \\
\text {-Fz: } 75\end{array}$ & $\begin{array}{l}{ }^{*} \mathrm{GV}: 1 \\
\mathrm{M}-\mathrm{II}: 6 \\
-\mathrm{Fz}: 40\end{array}$ & $\begin{array}{l}{ }^{*} \mathrm{GV}: 0 \\
\mathrm{M}-\mathrm{II}: 5 \\
-\mathrm{FZ}: 13\end{array}$ & & & \\
\hline
\end{tabular}

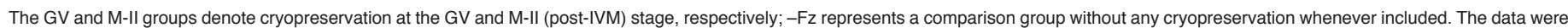

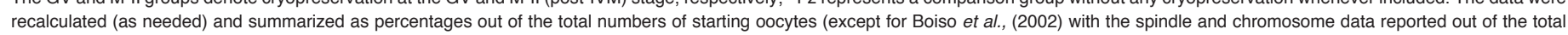

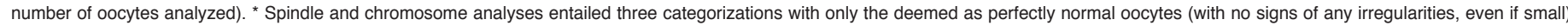

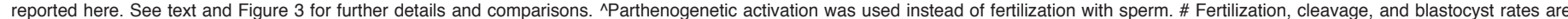

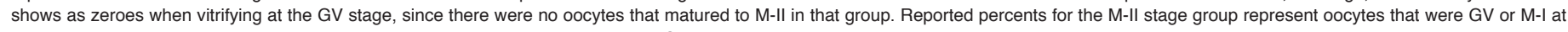
the start of culture since there weren't sufficient data to extrapolate the data for the GV oocytes only. 
design (Fasano et al., 2012; Wang et al., 2012). However in the Fasano et al., (2012) study, GV and M-I failed to mature oocytes were both included, and it is not clear that GV oocytes from a single patient were randomly allocated to either treatment groups (versus a random allocation of GV and M-I oocytes together). Five and three studies used a slow-freezing and vitrification protocol, respectively. Three of these eight studies did not test developmental competence in vitro, but rather focused on an assessment of spindle and chromosome organization (not all of which relied on a powerful and most reliable three-dimensional imaging with confocal laser-scanning microscopy) (Table 3).

When assessing results across studies, trends can be gathered (Table 3); one rather small study ( $n=52$ and $68 \mathrm{GV}$ s in each treatment arm) that gave unusually low results (even with maturation prior to vitrification) is excluded from the following discussion (Fasano et al., 2012). It is apparent that most studies report comparable survival rates, with maturation systematically compromised when cryopreserving at the GV stage (30-56\% versus $70-85 \%$ when cryopreserving at the GV versus $\mathrm{M}-$-Il stage). In all studies using oocytes from stimulated ovaries, fertilization rates were lower when cryopreserving GV (17-35\%) when compared to M-II (29-59\%) oocytes. This was also the case for the progression to cleavage stages (16-29\% and $26-59 \%$ when cryopreserving at the GV and $\mathrm{M}$-II stage, respectively), although it is important to note that the top percentages were always from a study with a small sample size of a total of 50 oocytes between the two groups (Chung et al., 2000). Development to blastocyst ranged from $0-12 \%$ and $0-23 \%$ when cryopreserving before and after maturation, respectively (with again top percentages from a same small study).

There is only a single study that included a group of oocytes from an unstimulated source (Chung et al., 2000). Importantly, it is a preliminary study with very small sample sizes ( $n=53$ and 50 oocytes from unstimulated and stimulated ovaries, respectively). Nonetheless, the results may suggest that outcomes are better when using oocytes with, when compared to without, stimulation, particularly when freezing after IVM at the M-II stage. Given that all other studies comparing freezing at the GV or M-II stage relied on the use of immature oocytes following ovarian stimulation, potential differences with unstimulated sources of oocytes must thus be considered.

The types of cryopreservation protocols also merit consideration. However, a single study evaluated the in vitro developmental competence of slow-frozen oocytes in contrast to four studies with vitrified oocytes. Further, two of the five slow-freezing studies used a choline-based rather than sodium-based protocol (Goud et al., 2000; Wang et al., 2012). But with different outcome measures across the studies, no conclusions can be reached about any potential effects of the use of either conventional or sodium-substituted slow-freezing. When compared within a single study (albeit not comparing sibling oocytes), improved outcomes (maturation and cleavage) were reported for the slow-freezing of GV oocytes with a choline-based when compared to a conventional, sodium-based slow-freezing protocol (Goud et al., 2000). More studies are thus needed to draw conclusions on the best cryopreservation protocol for use in either GV or in vitro matured M-II oocytes.

Three studies assessed spindles and chromosomes in M-II oocytes that were slow-frozen at either the GV or M-II (post-IVM) stage (Baka et al., 1995; Boiso et al., 2002; Wang et al., 2012). Results vary greatly with respect to reported ranges of normalcy
(Table 3), as well as conclusions reached for the best stage to freeze immature oocytes at. Some of these variations may be explained by differences in assessment methodology and criteria (see previous discussion); regardless, further studies remain to establish with more certainty the spindle organization of immature oocytes cryopreserved at the GV or M-II stage. The exact and actual impact of slight chromosomal disarrangements (as observed by DNA fluorescence alone) is unknown (Fig. 3). The euploidy of embryos that result from cryopreserved immature oocytes remains to be determined. There are no cytogenetic evaluations comparing freezing at GV and M-II stages. However, when cryopreserving at the GV stage, a preliminary cytogenetic assessment of vitrified immature oocytes reports karyotypes comparable to non-vitrified oocytes (Van Blerkom and Davis, 1994). The proportion of aneuploidy was also similar in M-II oocytes following IVM of cryopreserved GV stage oocytes when compared to non-frozen oocytes and exposure to cryoprotectant alone, although polyploidy was increased (Park et al., 1997). A more indirect assessment included a karyotyping of blastocysts that resulted from vitrification of immature oocytes after IVM; for the 7 blastocysts analyzed, there was no detected abnormality in chromosome numbers (Chung et al., 2000). While reassuring, these early results merit confirmation in other statistically powered studies.

Taken together, the eight comparative studies presented in Table 3 suggest that the outcomes measured to date are improved (even if not always significantly) when cryopreserving at the M-II stage following IVM rather than at the GV stage prior to IVM. This may not necessarily be the final answer to the question of when to freeze immature oocytes. Certainly, success rates remains unacceptably low. As aforementioned, weaknesses exist with some of the past studies, and other aspects must be considered (as discussed next).

\section{Where does the future lie?}

Studies to date point to the difficulties when cryopreserving immature GV human oocytes. Unlike what originally postulated, but as often still put forth, the GV stage does not appear to resist freezing injuries better than the M-II post-IVM stage. On the contrary, current evidence indicates that GV stage oocytes are particularly susceptible to cryodamages. Future efforts should thus aim to improve the efficacy of GV cryopreservation, and pertinent considerations are discussed next.

\section{Challenges posed by germinal vesicle freezing}

It is relevant to consider why GV oocytes may be particularly challenging to freeze after all. Since oocytes mature spontaneously upon removal from the follicle, catching the oocyte in the 'meiotic act' rather than its truly arrested stage may pose an unforeseen difficulty when attempting the cryopreservation of GV oocytes. If cryopreserved during germinal vesicle breakdown, the chances for cryodamages may be increased, with targets including condensing chromosomes, nuclear envelope breakdown, organelle remodeling, and changes in microtubule stability for early spindle formation and organelle redistribution. Due to other effects, the postulated benefits of cryopreserving at the actual GV stage may thus not become apparent. In human, a single study used a chemical treatment (with dbcAMP) to synchronize the retrieved GV oocytes (Goud et al., 2000), but the effectiveness of this approach was not compared with an untreated group. It is relevant to note that in animal models, 
meiotic arresters were tested together with cryopreservation (in the bovine for instance (Diez et al., 2005); no benefits are yet reported, although there are issues and detrimental effects associated with the current arresting strategies alone.

The vast majority of studies cryopreserved oocytes that were denuded and thus devoid of cumulus cells during both maturation and cryopreservation steps. Exceptions include the slow-freezing of GV or M-II (post-IVM) oocytes with 1-3 remaining cumulus cell layers (Goud et al., 2000) and the initial maturation as COCs in the first 24 hours, albeit followed by maturation without cumulus cells in the last 24 hours and cooling/ warming steps performed on denuded oocytes (studies in R.C. Chian's laboratory). When freezing immature oocytes, the presence and extent of a cumulus cell vestment may influence results. With the known roles of cumulus cells for optimal oocyte maturation, the lack of cumulus cells is a limitation in any IVM culture system using leftover oocytes from ICSI. However, ultrastructural evaluation of vitrified intact bovine and mouse COCs showed disruption of the intercellular communications between the oocyte and cumulus cells (Fuku et al., 1995; Ruppert-Lingham et al., 2003), and promising results have been obtained with the cryopreservation of cumulus-free bovine immature oocytes followed by co-culture with intact COCs during IVM (Luciano et al., 2009). Significant challenges remain with the cryopreservation of intact COCs (Goud et al., 2000; Tharasanit et al., 2009; Zhou et al., 2010). Mechanistically, it may not be possible to use a single cryopreservation protocol for the two cell types making up the COC; this may be due to significant differences in the size, shape, and permeability of the cells, an inability to preserve the delicate and highly dynamic interactions between the oocyte and cumulus cells and/or an ineffectiveness of cryoprotectants to penetrate the layers of the COC. Should the cryopreservation of cumulus-free oocytes prove to be a superior approach, alternative maturation approaches may help alleviate the absence of cumulus cells; for instance, one could envision the re-establishment of cumulus cell-oocyte interactions following the separate freezing of each cell type and the use of a three-dimensional co-culture system (Combelles et al., 2005). Taken together, previous studies point to the challenges with freezing intact COCs, and the benefits and drawbacks of freezing intact when compared to denuded complexes remain to be established in human. Clearly, there is no current consensus on the consequences of the presence or absence of cumulus cells during cryopreservation.

Cytoplasmic microtubules may not be as stable as presumed in GV oocytes, which were shown to lack acetylated microtubules in human (Combelles et al., 2002). Microtubule acetylation is associated with increased stability, the absence of which may render oocytes more sensitive to cryoinjury. A GV-stage oocyte is also characterized by a richness of membrane-bound organelles that still need to undergo major changes, including the redistribution of cortical granules, smooth endoplasmic reticulum, and mitochondria. It is conceivable that cryopreservation interferes with these penultimate, yet crucial, preparatory steps that the cytoplasm of an immature oocyte remains to undergo prior to fertilization. While the meiotic spindle may be able to recover following thawing/ warming, damages to cellular components in a GV oocyte may perhaps occur irreversibly.

It is likely that distinct cryopreservation protocols need to be developed for use in either GV or M-II oocytes; all of the protocols employed to date with immature oocytes are ones previously developed for use in early embryos, and such protocols may not necessarily be optimal in a cell with significantly different features. For instance during slow-freezing, the effects of sucrose concentrations varied with the oocyte meiotic stage (Chen et al., 2004). Interestingly, bovine GV oocytes are characterized by decreased water and solute permeability when compared to M-II (Agca et al., 1998; Wang et al., 2010). Differences in lipid composition and membrane properties would affect osmotic stress and cryoprotectant penetration during cryopreservation. Yet, no attempts have yet tailored the cryopreservation protocol to the specific oocyte meiotic stage, and an increased understanding of ways in which human GV and M-II oocytes differ will direct future endeavors.

One must not forget that the use of immature oocytes in fertility preservation relies on IVM, whether following or prior to freezing. However, the IVM technique remains unperfected without any significant improvements in the last decades. As such, IVM represents a current hurdle when cryopreserving immature oocytes. For instance, the IVM media used were all designed to mature intact cumulus-oocyte complexes, and not denuded oocytes that have failed to mature in vivo, as most cryopreservation studies have relied on thus far. Advances in the field of IVM should lead to significant improvements with oocyte freezing, and of course the continued testing of novel IVM system should be undertaken in combination with state-of-the-art cryopreservation approaches.

\section{Cryopreserving at intermediate meiotic stages}

All studies discussed thus far cryopreserved oocytes at either the GV or M-II stage, specifically after IVM of immature oocytes that were GV at the start of culture. However, one may posit whether the use of intermediate meiotic stages may prove superior in terms of clinical efficacy. Oocytes with neither an intact GV nucleus nor a polar body are scored as metaphase-I (M-I) oocytes. If M-I oocytes are retrieved, cryopreservation may be performed at the M-I or M-II stage following IVM. To date, results indicate that oocytes deemed $\mathrm{M}-\mathrm{I}$ at retrieval yield improved outcomes when compared to GV oocytes (Chang et al., 2008; Fasano et al., 2010; Versieren et al., 2011; Zhang et al., 2011; Fasano et al., 2012). However, there isn't a direct clinical utility of retrieved M-I oocytes for cancer patients since GV oocytes would be obtained instead. In contrast, the in vitro maturation of GV oocytes up to the M-I stage followed by cryopreservation merits consideration. A single study vitrified oocytes after 8-15 hrs IVM so presumably at the M-I stage, followed by an additional IVM period following warming (Chung et al., 2000); the study is too small and preliminary in nature to conclude on any advantages or detriments of cryopreserving at the M-I versus GV or M-Il stages. Although caution must be exercised when extrapolating findings on cryosensitivity across species, the meiotic stage influenced outcomes in the bovine, albeit in a conflicting pattern (Hochi et al., 1998; Men et al., 2002).

\section{Cellular and molecular evaluations}

The evaluation of clinical efficiency is of course critical to all studies. Nonetheless, much insight can still be gained from routine and thorough assessments of cellular and molecular damages, including the unraveling of potential targets for optimization. It generally proves useful to identify cellular abnormalities following cryopreservation since future efforts could get at the root of the problem. For example, a systematic analysis of all oocytes (even ones without a polar body) revealed aberrations in cell 
cycle regulation, specifically with a heightened propensity to activate spontaneously for oocytes that were slow-frozen at the GV stage (Combelles et al., 2011; Wang et al., 2012). Abnormalities in nuclear and cytoplasmic components were reported following the vitrification of immature oocytes at the GV stage, including nucleolar disorganization, premature chromatin condensation, and organelle relocalization (Van Blerkom and Davis, 1994). The cortical actin cytoskeleton may also be subject to alterations, as demonstrated following the maturation of vitrified GV stage oocytes (Combelles et al., 2011). Studies should undoubtedly continue to evaluate spindles and chromosomes; however, assessment should be expanded to include a panel of measures, among which may be DNA damage, gene expression (Monzo et al., 2012), oocyte physiology (Gardner et al., 2007), and organelle function such as integrity of the endoplasmic reticulum (Lowther et al., 2009), as reported in cryopreserved in vivo matured oocytes. One step in a promising direction pertains to a recent confirmation that the methylation profiles of two imprinting control regions did not change with vitrification at the GV stage followed by IVM (AI-Khtib et al., 2011).

\section{Source of oocytes for experimental studies}

The vast majority of reports on the cryopreservation of immature oocytes relied on a source of material that is not optimal, since oocytes that failed-to-mature in vivo do not represent the clinical material that would be available for fertility preservation. The clinical use of optimal immature human oocytes for experimental studies is extremely limited by availability. Given the infancy of the field of immature oocyte cryopreservation, together with current challenges, initial testing should be conducted on available oocyte sources. Only with years of experience and multiple protocols and markers evaluated in experimental oocytes will we reach a point when we can begin applying findings to the clinical realm. The best source of material for this work is, undeniably, oocytes retrieved as intact cumulus-oocyte-complexes after no or minimal ovarian stimulation. Such oocytes are extremely scarce and difficult to obtain, and one may argue against using them experimentally at this juncture. With lessons learnt from invaluable research material, together with a deeper understanding of the cellular sensitivities of immature oocytes to cryopreservation, we may then be in a position to apply our novel knowledge to clinical studies.

However, limitations with the use of failed-to-mature oocytes must not be ignored. For instance, the quality of these oocytes is inherently variable since they originate from a heterogeneous pool of antral follicles; the oocytes also failed to mature in vivo in spite of exogenous ovarian stimulation, thereby indicating their compromised developmental potential from the start. As a result, these oocytes may be less able to withstand stresses induced by cryopreservation. This is however conjecture; in remaining critical, the pristine quality of oocytes obtained for IVM may also be called into question since immature oocytes have not yet completed their developmental program in the follicle.

\section{Past uses of immature oocytes for fertility preservation in cancer patients}

Despite the invaluable insight that can be gleaned from studies with experimental material, extrapolation to clinical situation shall be foreseen. A few studies directly document the potential utility of immature oocytes in cancer patients. Early reports demonstrate the successful retrieval, maturation, and vitrification of immature oocytes that were obtained from excised ovaries prior to ovarian tissue banking in a total of 15 cancer patients between 18 and 38 years of age (Revel et al., 2003; Isachenko et al., 2004; Huang et al., 2008). More recently, immature oocytes were also obtained from 76 patients (5-35 years old) undergoing ovarian tissue cryopreservation to preserve their fertility (Revel et al., 2009; Fasano et al., 2011). Oocytes were matured in vitro and vitrified at the M-II stage. Immature oocytes can thus be obtained from ovarian tissue biopsies; while maturation rates were low (31\% and 34\% overall), mature oocytes were vitrified regardless of the phase of the menstrual cycle, use of oral contraception, or the age of the patient, even if pre-pubertal or adolescent (Fasano et al., 2011; Revel et al., 2009). There are thus alternative strategies that involve immature oocytes and that may be used along other approaches for fertility preservation. Since the freezing of ovarian tissue targets the use of primordial and primary follicles without preserving oocytes from antral follicles, gametes at later stages of oogenesis would become wasted. As a result, strategies that target both ovarian tissue and oocyte freezing shall heighten a patient's options and chance at childbearing.

Another approach entails the retrieval of immature oocytes throughout the menstrual cycle with only hCG priming 38-40 hours prior to retrieval; following IVM, mature oocytes are either vitrified or fertilized followed by vitrification of the resulting embryo. Embryos may thus be considered as the stage to freeze at, even when using immature oocytes as the starting material and as long as sperm is available. Two studies from the same group report on maturation rates of $59 \%$ and $73 \%$ from 66 and 38 breast cancer patients, respectively (Huang et al., 2010; Shalom-Paz et al., 2010). The yields of vitrified oocytes (7-8) and embryos (4-5) per patient were encouraging, although there isn't yet any follow-up use of this cryopreserved cellular material. If tangible, it may be best to retrieve oocytes directly from patients that are monitored and primed with hCG, an approach that may yield superior and more consistent results across patients when compared to the aspiration of oocytes from excised ovaries. Conversely, the cryopreservation of ovaries together with oocytes may provide an efficient way to ensure that embryos are available when the patient wishes to become pregnant. Multiple options thus exist for the retrieval of immature oocytes for fertility preservation although information on clinical efficacy is not yet available. Indeed, while oocytes from an immature source are cryopreserved, they remain to be thawed/warmed and used clinically by cancer patients. Due to the experimental nature of the procedures, caution is thus warranted, together with appropriate monitoring.

\section{Other potential opportunities for improvements}

The field is burgeoning and it provides a fertile ground for future advances; some areas of focus were presented above, including the cryopreservation protocol and oocyte types (e.g. ovarian sources, retrieval conditions, presence or absence of cumulus cells). Experimental manipulations may also help augment the developmental potential of cryopreserved immature oocytes. A preliminary study tested the use of artificial oocyte activation to improve the developmental potential of vitrified immature oocytes, although outcomes remained poor (Liu et al., 2011). Alternatively, the oocytes may be manipulated in ways that aim to increase the resistance of the oocyte to the stresses of cryopreservation. In this way, the oocytes may be conditioned or prepared to resist cryoin- 
juries. A pilot study examined the effect of the drug taxol to help stabilize the microtubule cytoskeleton prior to cryopreservation (Fuchinoue et al., 2004). Results indicated some improvements, as previously suggested in animal models. In a cat model, GV stage oocytes possessed increased developmental competence when treated with a drug that promotes chromatin compaction prior to vitrification (Comizzoli et al., 2009). Of course, the safety of any chemical approach must be ensured and may preclude application in human oocytes. More recently, innovative approaches that take advantage of controlled sublethal physiological stresses have been explored in animal models. The rationale behind a 'stress for stress tolerance' approach lies in the induced ability of the exposed oocytes to resist stresses associated with cryopreservation, through perhaps increased synthesis or activation of endogenous proteins/mechanisms that afford protection to the oocyte (reviewed by Pribenszky et al., 2010).

Certain confounders may influence outcomes and the clinical efficacy of cryopreserving immature oocytes, including patient age (Wang et al., 2012). Age is relevant to consider since a patient may be undergoing cancer treatment in her thirties prior to her own chance at becoming pregnant. These patients need personalized options, and we must thus aim to understand any differences in outcomes with age. Experimental studies on the cryopreservation of immature oocytes have been based on a wide range of oocyte origin, notably from patients of variable infertility diagnosis. Any influences of infertility diagnosis on the success of cryopreservation must also be taken into account, since most cancer patients would presumably be of normal fertility at the time of oocyte retrieval.

\section{Conclusions}

While an increasing number of reports document feasibility, the clinical efficiency of fertility preservation using immature oocytes remains low or uncertain. The field thus needs to reach a point at which immature oocytes can be cryopreserved reliably and safely. Albeit still preliminary, the evidence to date suggests improvements when cryopreserving immature oocytes after IVM to the M-II stage. Nonetheless, future efforts should not ignore the eventuality of satisfactory outcomes with cryopreservation at the GV stage. As long as protocols that are optimal for each meiotic stage are developed, we may be able to cryopreserve GV and/or M-II oocytes at acceptable efficiencies. In the future, studies should examine the influences of oocyte source and protocols on cellular as well as long-term clinical outcomes. IVM and cryopreservation are techniques that vary significantly with levels of expertise, selected protocols, and laboratory conditions. Also, sample sizes are often too small to interpret results. There is thus a dire need for more exhaustive experimentation of the potential utility of immature oocytes in fertility preservation. Results should be validated in large studies and confirmed independently by multiple groups.

Despite challenges, there are current promises with the cryopreservation of immature oocytes. Notably, Chian et al. (2009b) reported a $20 \%$ live-birth rate per cycle started when vitrifying M-II (post-IVM) oocytes in patients undergoing unstimulated IVM cycles (a total of 4 births). This success rate is from a small series of noncancer patients $(n=20)$, but it buttresses the validity of pursuing the use of immature oocytes in cryopreservation cycles. Given that this is the only study (other than 2 case reports/births) that documents in vivo developmental outcomes past the blastocyst stage, further work is warranted.

\section{Acknowledgements}

We thank Catherine Racowsky and Haiyan Wang for their assistance in procuring us oocytes for processing and imaging, as shown in Figures 2 and 3.

\section{References}

AGCA, Y., LIU, J., PETER, A.T., CRITSER, E.S., CRITSER, J.K. (1998). Effect of developmental stage on bovine oocyte plasma membrane water and cryoprotectant permeability characteristics. Mol. Reprod. Dev. 49: 408-415.

AL-KHTIB, M., PERRET, A., KHOUEIRY, R., IBALA-ROMDHANE, S., BLACHERE, T., GREZE, C., LORNAGE, J., LEFEVRE, A. (2011). Vitrification at the germinal vesicle stage does not affect the methylation profile of $\mathrm{H} 19$ and KCNQ1OT1 imprinting centers in human oocytes subsequently matured in vitro. Fertil. Steril. 95: 1955-1960.

ANCHAN, R.M., GINSBURG, E.S. (2010). Fertility concerns and preservation in younger women with breast cancer. Crit. Rev. Oncol. Hematol. 74: 175-192.

BAKA, S.G., TOTH, T.L., VEECK, L.L., JONES, H.W., JR., MUASHER, S.J., LANZENDORF, S.E. (1995). Evaluation of the spindle apparatus of in-vitro matured human oocytes following cryopreservation. Hum. Reprod. 10: 1816-1820.

BOISO, I., MARTI, M., SANTALO, J., PONSA, M., BARRI, P.N., VEIGA, A. (2002). A confocal microscopy analysis of the spindle and chromosome configurations of human oocytes cryopreserved at the germinal vesicle and metaphase II stage. Hum. Reprod. 17: 1885-1891.

CAO, Y., XING, Q., ZHANG, Z.G., WEI, Z.L., ZHOU, P., CONG, L. (2009). Cryopreservation of immature and in-vitro matured human oocytes by vitrification. Reprod. Biomed. Online. 19: 369-373.

CHANG, C.C., SHAPIRO, D.B., BERNAL, D.P., WRIGHT, G., KORT, H.I., NAGY, Z.P. (2008). Human oocyte vitrification: in-vivo and in-vitro maturation outcomes. Reprod. Biomed. Online. 17: 684-688.

CHEN, Z.J., LI, M., LI, Y., ZHAO, L.X., TANG, R., SHENG, Y., GAO, X., CHANG, C.H., FENG, H.L. (2004). Effects of sucrose concentration on the developmental potential of human frozen-thawed oocytes at different stages of maturity. Hum. Reprod. 19: 2345-2349.

CHIAN, R.C., BUCKETT, W.M., TULANDI, T., TAN, S.L. (2000). Prospective randomized study of human chorionic gonadotrophin priming before immature oocyte retrieval from unstimulated women with polycystic ovarian syndrome. Hum. Reprod. 15: 165-170.

CHIAN, R.C., GILBERT, L., HUANG, J.Y., DEMIRTAS, E., HOLZER, H., BENJAMIN A., BUCKETT, W.M., TULANDI, T., TAN, S.L. (2009a). Live birth after vitrification of in vitro matured human oocytes. Fertil. Steril. 91: 372-376.

CHIAN, R.C., HUANG, J.Y., GILBERT, L., SON, W.Y., HOLZER, H., CUI, S.J., BUCKETT, W.M., TULANDI, T., TAN, S.L. (2009b). Obstetric outcomes following vitrification of in vitro and in vivo matured oocytes. Fertil. Steril. 91: 2391-2398.

CHUNG, H.M., HONG, S.W., LIM, J.M., LEE, S.H., CHA, W.T., KO, J.J., HAN, S.Y., CHOI, D.H., CHA, K.Y. (2000). In vitro blastocyst formation of human oocytes obtained from unstimulated and stimulated cycles after vitrification at various maturational stages. Fertil. Steril. 73: 545-551.

COMBELLES, C.M., CEKLENIAK, N.A., RACOWSKY, C., ALBERTINI, D.F. (2002). Assessment of nuclear and cytoplasmic maturation in in-vitro matured human oocytes. Hum. Reprod. 17: 1006-1016.

COMBELLES, C.M., CEYHAN, S.T., WANG, H., RACOWSKY, C. (2011). Maturation outcomes are improved following Cryoleaf vitrification of immature human oocytes when compared to choline-based slow-freezing. J. Assist. Reprod. Genet. 28: 1183-1192.

COMBELLES, C.M., FISSORE, R.A., ALBERTINI, D.F., RACOWSKY, C. (2005). In vitro maturation of human oocytes and cumulus cells using a co-culture threedimensional collagen gel system. Hum. Reprod. 20: 1349-1358.

COMIZZOLI, P., WILDT, D.E., PUKAZHENTHI, B.S. (2009). In vitro compaction of germinal vesicle chromatin is beneficial to survival of vitrified cat oocytes. Reprod. Domest. Anim. 44 Suppl 2: 269-274.

CRIADO, E., ALBANI, E., NOVARA, P.V., SMERALDI, A., CESANA, A., PARINI, V., 
LEVI-SETTI, P.E. (2011). Human oocyte ultravitrification with a low concentration of cryoprotectants by ultrafast cooling: a new protocol. Fertil. Steril. 95: 1101-1103.

DIEZ, C., DUQUE, P., GOMEZ, E., HIDALGO, C.O., TAMARGO, C., RODRIGUEZ, A., FERNANDEZ, L., DE LA VARGA, S., FERNANDEZ, A., FACAL, N., CARBAJO, M. (2005). Bovine oocyte vitrification before or after meiotic arrest: effects on ultrastructure and developmental ability. Theriogenology. 64: 317-333.

EDGAR, D.H., GOOK, D.A. (2012). A critical appraisal of cryopreservation (slow cooling versus vitrification) of human oocytes and embryos. Hum. Reprod. Update.

FASANO, G., DEMEESTERE, I., ENGLERT, Y. (2012). In-vitro maturation of human oocytes: before or after vitrification? J. Assist. Reprod. Genet. 29: 507-512.

FASANO, G., MOFFA, F., DECHENE, J., ENGLERT, Y., DEMEESTERE, I. (2011). Vitrification of in vitro matured oocytes collected from antral follicles at the time of ovarian tissue cryopreservation. Reprod. Biol. Endocrinol. 9: 150.

FASANO, G., VANNIN, A.S., BIRAMANE, J., DELBAERE, A., ENGLERT, Y. (2010). Cryopreservation of human failed maturation oocytes shows that vitrification gives superior outcomes to slow cooling. Cryobiology. 61: 243-247.

FUCHINOUE, K., FUKUNAGA, N., CHIBA, S., NAKAJO, Y., YAGI, A., KYONO, K. (2004). Freezing of human immature oocytes using cryoloops with Taxol in the vitrification solution. J. Assist. Reprod. Genet. 21: 307-309.

FUKU, E., XIA, L., DOWNEY, B.R. (1995). Ultrastructural changes in bovine oocytes cryopreserved by vitrification. Cryobiology. 32: 139-156.

GARDNER, D.K., SHEEHAN, C.B., RIENZI, L., KATZ-JAFFE, M., LARMAN, M.G. (2007). Analysis of oocyte physiology to improve cryopreservation procedures. Theriogenology. 67: 64-72.

GOUD, A., GOUD, P., QIAN, C., VAN DER ELST, J., VAN MAELE, G., DHONT, M. (2000). Cryopreservation of human germinal vesicle stage and in vitro matured M II oocytes: influence of cryopreservation media on the survival, fertilization, and early cleavage divisions. Fertil. Steril. 74: 487-494.

HOCHI, S., ITO, K., HIRABAYASHI, M., UEDA, M., KIMURA, K., HANADA, A. (1998). Effect of nuclear stages during IVM on the survival of vitrified-warmed bovine oocytes. Theriogenology. 49: 787-796.

HUANG, J.Y., CHIAN, R.C., GILBERT, L., FLEISZER, D., HOLZER, H., DERMITAS, E., ELIZUR, S.E., GIDONI, Y., LEVIN, D., SON, W.Y., TAN, S.L. (2010). Retrieval of immature oocytes from unstimulated ovaries followed by in vitro maturation and vitrification: A novel strategy of fertility preservation for breast cancer patients. Am. J. Surg. 200: 177-183.

HUANG, J.Y., TULANDI, T., HOLZER, H., TAN, S.L., CHIAN, R.C. (2008). Combining ovarian tissue cryobanking with retrieval of immature oocytes followed by in vitro maturation and vitrification: an additional strategy of fertility preservation. Fertil. Steril. 89: 567-572.

ISACHENKO, E., RAHIMI, G., ISACHENKO, V., NAWROTH, F. (2004). In-vitro maturation of germinal-vesicle oocytes and cryopreservation in metaphase I/II: a possible additional option to preserve fertility during ovarian tissue cryopreservation. Reprod. Biomed. Online. 8: 553-557.

ISACHENKO, V., MONTAG, M., ISACHENKO, E., DESSOLE, S., NAWROTH, F., VAN DER VEN, H. (2006). Aseptic vitrification of human germinal vesicle oocytes using dimethyl sulfoxide as a cryoprotectant. Fertil. Steril. 85: 741-747.

LIU, Y., CAO, Y.X., ZHANG, Z.G., XING, Q. (2011). Artificial oocyte activation and human failed-matured oocyte vitrification followed by in vitro maturation. Zygote. 1-6.

LOWTHER, K.M., WEITZMAN, V.N., MAIER, D., MEHLMANN, L.M. (2009). Maturation, fertilization, and the structure and function of the endoplasmic reticulum in cryopreserved mouse oocytes. Biol. Reprod. 81: 147-154.

LUCIANO, A.M., FRANCIOSI, F., LODDE, V., PERAZZOLI, F., SLEZAKOVA, M., MODINA, S. (2009). Cryopreservation of immature bovine oocytes to reconstruct artificial gametes by germinal vesicle transplantation. Reprod. Domest. Anim. 44: 480-488.

MANDELBAUM, J., ANASTASIOU, O., LEVY, R., GUERIN, J.F., DE LAROUZIERE, V., ANTOINE, J.M. (2004). Effects of cryopreservation on the meiotic spindle of human oocytes. Eur. J. Obstet. Gynecol. Reprod. Biol. 113 Suppl 1: S17-23.

MANDELBAUM, J., JUNCA, A.M., PLACHOT, M., ALNOT, M.O., SALAT-BAROUX, J., ALVAREZ, S., TIBI, C., COHEN, J., DEBACHE, C., TESQUIER, L. (1988). Cryopreservation of human embryos and oocytes. Hum. Reprod. 3: 117-119.

MEN, H., MONSON, R.L., RUTLEDGE, J.J. (2002). Effect of meiotic stages and maturation protocols on bovine oocyte's resistance to cryopreservation. Theriogenology. 57: 1095-1103.
MONZO, C., HAOUZI, D., ROMAN, K., ASSOU, S., DECHAUD, H., HAMAMAH, S. (2012). Slow freezing and vitrification differentially modify the gene expression profile of human metaphase II oocytes. Hum. Reprod. 27: 2160-2168.

NOGUEIRA, D., SADEU, J.C., MONTAGUT, J. (2012). In vitro oocyte maturation: current status. Semin. Reprod. Med. 30: 199-213.

PARK, S.E., SON, W.Y., LEE, S.H., LEE, K.A., KO, J.J., CHA, K.Y. (1997). Chromosome and spindle configurations of human oocytes matured in vitro after cryopreservation at the germinal vesicle stage. Fertil. Steril. 68: 920-926.

PRIBENSZKY, C., VAJTA, G., MOLNAR, M., DU, Y., LIN, L., BOLUND, L., YOVICH, J. (2010). Stress for stress tolerance? A fundamentally new approach in mammalian embryology. Biol. Reprod. 83: 690-697.

REVEL, A., KOLER, M., SIMON, A., LEWIN, A., LAUFER, N., SAFRAN, A. (2003). Oocyte collection during cryopreservation of the ovarian cortex. Fertil. Steril. 79: 1237-1239.

REVEL, A., REVEL-VILK, S., AIZENMAN, E., PORAT-KATZ, A., SAFRAN, A., BENMEIR, A., WEINTRAUB, M., SHAPIRA, M., ACHACHE, H., LAUFER, N. (2009). At what age can human oocytes be obtained? Fertil. Steril. 92: 458-463.

RUPPERT-LINGHAM, C.J., PAYNTER, S.J., GODFREY, J., FULLER, B.J., SHAW, R.W. (2003). Developmental potential of murine germinal vesicle stage cumulus-oocyte complexes following exposure to dimethylsulphoxide or cryopreservation: loss of membrane integrity of cumulus cells after thawing. Hum. Reprod. 18: 392-398.

SHALOM-PAZ, E., ALMOG, B., SHEHATA, F., HUANG, J., HOLZER, H., CHIAN, R.C., SON, W.Y., TAN, S.L. (2010). Fertility preservation for breast-cancer patients using IVM followed by oocyte or embryo vitrification. Reprod. Biomed. Online. 21: 566-571.

SON, W.Y., PARK, S.E., LEE, K.A., LEE, W.S., KO, J.J., YOON, T.K., CHA, K.Y. (1996). Effects of 1,2-propanediol and freezing-thawing on the in vitro developmental capacity of human immature oocytes. Fertil. Steril. 66: 995-999.

STACHECKI, J.J., COHEN, J. (2004). An overview of oocyte cryopreservation. Reprod. Biomed. Online. 9: 152-163.

THARASANIT, T., COLLEONI, S., GALLI, C., COLENBRANDER, B., STOUT, T.A. (2009). Protective effects of the cumulus-corona radiata complex during vitrification of horse oocytes. Reproduction. 137: 391-401.

TOTH, T.L., BAKA, S.G., VEECK, L.L., JONES, H.W., JR., MUASHER, S., LANZENDORF, S.E. (1994a). Fertilization and in vitro development of cryopreserved human prophase I oocytes. Fertil. Steril. 61: 891-894.

TOTH, T.L., LANZENDORF, S.E., SANDOW, B.A., VEECK, L.L., HASSEN, W.A., HANSEN, K., HODGEN, G.D. (1994b). Cryopreservation of human prophase I oocytes collected from unstimulated follicles. Fertil. Steril. 61: 1077-1082.

TUCKER, M.J., WRIGHT, G., MORTON, P.C., MASSEY, J.B. (1998). Birth after cryopreservation of immature oocytes with subsequent in vitro maturation. Fertil. Steril. 70: 578-579.

VAN BLERKOM, J., DAVIS, P.W. (1994). Cytogenetic, cellular, and developmental consequences of cryopreservation of immature and mature mouse and human oocytes. Microsc. Res. Tech. 27: 165-193.

VERSIEREN, K., HEINDRYCKX, B., O'LEARY, T., DE CROO, I., VAN DEN ABBEEL, E., GERRIS, J., DE SUTTER, P. (2011). Slow controlled-rate freezing of human in vitro matured oocytes: effects on maturation rate and kinetics and parthenogenetic activation. Fertil. Steril. 96: 624-628.

WANG, H., RACOWSKY, C., COMBELLES, C.M. (2012). Is it best to cryopreserve human cumulus-free immature oocytes before or after in vitromaturation? Cryobiology.

WANG, X., AL NAIB, A., SUN, D.W., LONERGAN, P. (2010). Membrane permeability characteristics of bovine oocytes and development of a step-wise cryoprotectant adding and diluting protocol. Cryobiology. 61: 58-65.

WU, J., ZHANG, L., WANG, X. (2001). In vitro maturation, fertilization and embryo development after ultrarapid freezing of immature human oocytes. Reproduction. 121: 389-393.

XU, M., PAVONE, M.E., WOODRUFF, T. (2011). Fruitful progress to fertility: preserving oocytes from chemodestruction. Nat. Med. 17: 1562-1563.

ZHANG, Z., LIU, Y., XING, Q., ZHOU, P., CAO, Y. (2011). Cryopreservation of human failed-matured oocytes followed by in vitro maturation: vitrification is superior to the slow freezing method. Reprod. Biol. Endocrinol. 9: 156.

ZHOU, X.L., AL NAIB, A., SUN, D.W., LONERGAN, P. (2010). Bovine oocyte vitrification using the Cryotop method: effect of cumulus cells and vitrification protocol on survival and subsequent development. Cryobiology. 61: 66-72. 


\section{Further Related Reading, published previously in the Int. J. Dev. Biol.}

Highly efficient cryopreservation of human induced pluripotent stem cells using a dimethyl sulfoxide-free solution

Tatsuya Nishigaki, Yuji Teramura, Akira Nasu, Kei Takada, Junya Toguchida and Hiroo Iwata Int. J. Dev. Biol. (2011) 55: 305-311

Generation of germ-line chimera zebrafish using primordial germ cells isolated from cultured blastomeres and cryopreserved embryoids

Yutaka Kawakami, Rie Goto-Kazeto, Taiju Saito, Takafumi Fujimoto, Shogo Higaki, Yoshiyuki Takahashi, Katsutoshi Arai and Etsuro Yamaha

Int. J. Dev. Biol. (2010) 54: 1493-1501

A simple and efficient cryopreservation method for primate embryonic stem cells Tsuyoshi Fujioka, Kentaro Yasuchika, Yukio Nakamura, Norio Nakatsuji and Hirofumi Suemori Int. J. Dev. Biol. (2004) 48: 1149-1154

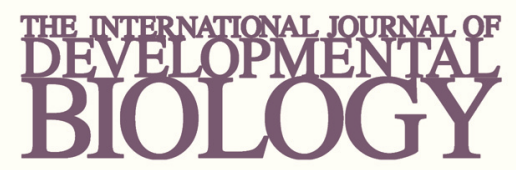

Volume 54 Nos. 6/7
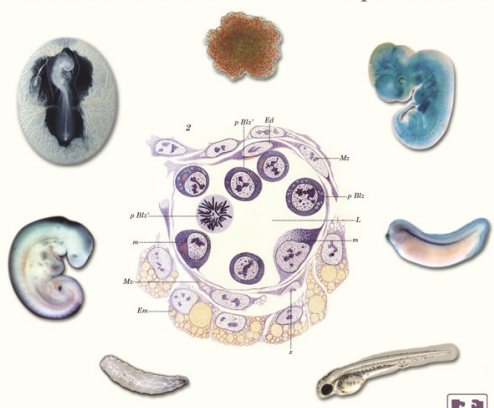

Developmental Hematopoiesis
5 yr ISI Impact Factor $(2011)=2.959$
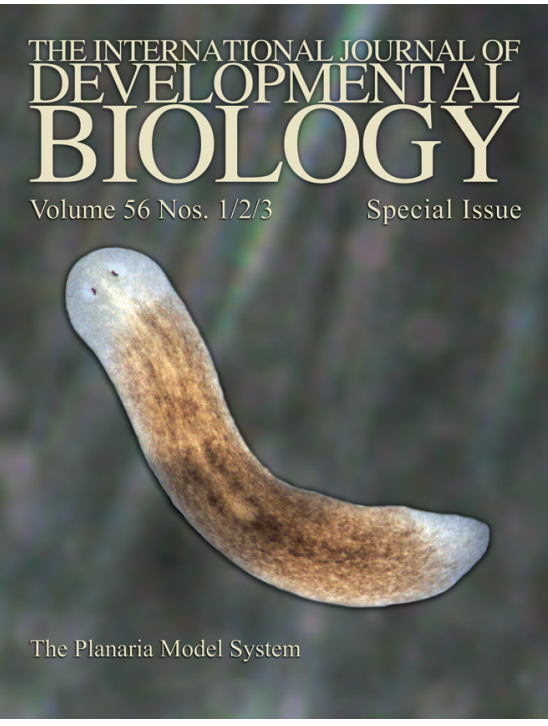

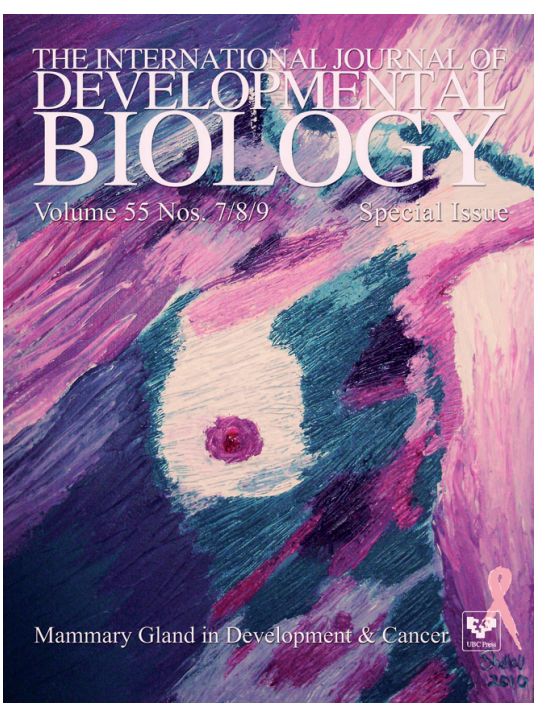

THE INTERNATIONAL JOURNAL OF DEVELOPMIENTAI 0100

Volume 55 Nos. $4 / 5$

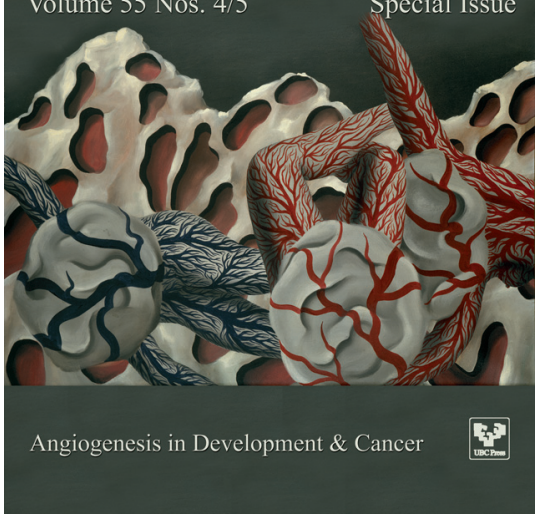

